\title{
Article
}

\section{Religious Attendance Moderates the Environmental Effect on Prosocial Behavior in Nigerian Adolescents}

\author{
Yoon-Mi Hur ${ }^{1}$, Hoe-Uk Jeong ${ }^{2}$, Frances Ajose ${ }^{3}$ and Ariel Knafo-Noam ${ }^{4}$ \\ ${ }^{1}$ Research Institute for Welfare Society, Mokpo National University, Jeonnam, South Korea, ${ }^{2}$ Department of Education, Mokpo National University, \\ Jeonnam, South Korea, ${ }^{3}$ Clinical Sciences, Lagos State University College of Medicine, Lagos, Nigeria and ${ }^{4}$ Department of Psychology, The Hebrew \\ University of Jerusalem, Jerusalem, Israel
}

\begin{abstract}
There is a growing body of literature linking religious attendance to prosocial behavior (PB). The main purposes of the present study were to estimate genetic and environmental influences on the frequency of religious attendance (FRA) and to explore whether and how FRA moderates genetic and/or environmental influences on PB. As part of the Nigerian Twin and Sibling Study, 2860 (280 monozygotic male, 417 monozygotic female, 544 dizygotic male, 699 dizygotic female, and 920 opposite-sex dizygotic) twins (mean age $=14.2$ years; SD = 1.7 years; age range $=12-18$ years) completed a questionnaire regarding FRA and a PB scale. Similar to the findings from western twin samples, FRA showed substantial shared environmental influences of $74 \%(95 \% \mathrm{CI}=69 \%, 78 \%)$, with absence of genetic effects. The phenotypic correlation between FRA and PB was modest but positive and significant $(r=.12 ; p<.01)$, suggesting that PB is higher among more frequent attenders than among less frequent attenders. The results of gene-environment $(G \times E)$ interaction model-fitting analysis revealed that FRA changed individual environmental experiences rather than genetic effects on PB such that while genetic variance was stable, non-shared environmental variance declined, leading the total phenotypic variance of PB to decrease with increasing levels of religious attendance.
\end{abstract}

Keywords: prosocial behavior; religious attendance; $G \times E$ interaction model; twin; Africans; adolescence

(Received 21 November 2018; accepted 5 December 2018)

The 'religious prosociality hypothesis' states that religious belief or concept facilitates prosocial behavior (PB) such as giving to charity, volunteering or helping strangers (Norenzayen \& Shariff, 2008). Since the publication of the religious prosociality hypothesis, the relationship between religiousness and PB has been hotly debated in psychology and the general public. Although a few researchers have found negative relationships between religiousness and PB (e.g., Decety et al., 2015), most correlational studies have shown modest but positive relationships between the two (Benson et al., 2006; Furrow et al., 2004). Experimental research that induced religious thinking and subsequently measured $\mathrm{PB}$ of subjects yielded positive relationships as well. For example, a recent meta-analysis of religious priming studies has shown that religious reminders increased $\mathrm{PB}$, with an average effect size of Hedges' $g=0.27(95 \% \mathrm{CI}=0.15,0.40)$ (Shariff et al., 2016).

While the relationship between religiousness and PB has been relatively well established, how genetic and environmental effects combine to influence this relationship remains poorly understood. In an attempt to understand the causal mechanism of the relationship, Koenig et al. (2007) have applied a bivariate genetic model to adult male twin data for altruistic behavior and religiousness

\footnotetext{
Author for correspondence: Yoon-Mi Hur, Email: ymhur@mokpo.ac.kr Cite this article: Hur Y-M, Jeong H-U, Ajose F, and Knafo-Noam A. (2019) Religious Attendance Moderates the Environmental Effect on Prosocial Behavior in Nigerian Adolescents. Twin Research and Human Genetics 22: 42-47, https://doi.org/10.1017/ thg.2018.71
}

and found that both common genetic and shared environmental variances explained the association.

Twin studies of PB on the basis of western and Asian samples have shown that about $30-50 \%$ of the variance in children and adolescents were attributable to genetic influences, with the remaining variance being predominantly due to non-shared environmental influences and measurement error (Gregory et al., 2009; Hur \& Rushton, 2007; Knafo \& Plomin, 2006; Scourfield et al., 2004). In contrast, most twin studies of religious attendance have indicated substantial influence of shared environmental factors with the absence of genetic factors in childhood and adolescence (Boomsma et al., 1999; Bradshaw \& Ellison, 2008; Truett et al., 1992), although some studies have found reverse patterns in adulthood (Hvidtjørn et al., 2013; Kendler \& Myers, 2009; Kirk et al., 1999; Koenig et al., 2005). For example, in the Kendler and Myers study (2009), shared environmental factors explained about $50 \%$ of the variance of frequency of church attendance in childhood and adolescence. In adulthood, however, these factors declined dramatically to a statistically non-significant amount. In contrast, genetic and non-shared environmental factors progressively increased with increasing age, accounting for about $60 \%$ and $40 \%$, respectively, of the variance in adulthood. These age-related changes may be attributable to a decreasing family influence as children become older, and there are increasing influences from individual life events (e.g., marriage/divorce, birth of own child, accidents, illness). Results on sex difference in genetic

(c) The Author(s) 2019. This is an Open Access article, distributed under the terms of the Creative Commons Attribution-NonCommercial-NoDerivatives licence (http://creativecommons. org/licenses/by-nc-nd/4.0/), which permits non-commercial re-use, distribution, and reproduction in any medium, provided the original work is unaltered and is properly cited. The written permission of Cambridge University Press must be obtained for commercial re-use or in order to create a derivative work. 
and environmental influences on the frequency of church attendance are mixed: while some studies (e.g., Truett et al., 1992, 1994) have reported that females had greater genetic and smaller shared environmental influences on church attendance than did males, others have found the opposite pattern (e.g., Eaves et al., 2008; Winter et al., 1999).

Twin studies of PB and religious attendance have rarely been undertaken among Africans. Recently, using a sample of Nigerian public school twins as used in the present study, we demonstrated that the magnitudes of genetic and environmental influences on $\mathrm{PB}$ were within the range of those found in European and East Asian samples. Specifically, genetic and non-shared environmental influences on PB were $0.38(95 \% \mathrm{CI}=0.31,0.46)$ and $0.62(95 \%$ $\mathrm{CI}=0.54,0.69$ ), respectively (Hur et al., 2017). These findings were surprising given the large differences in environments and genetic variations between African and non-African populations (Campbell \& Tishkoff, 2008).

Previous studies have demonstrated that religiousness modified the genetic and/or environmental effects on adolescents' behaviors. For example, using the gene-environment $(G \times E)$ interaction model-fitting approach (Purcell, 2002), Button et al. (2010) have shown that genetic variance in problem alcohol use decreased significantly with increasing levels of religiosity in both males and females during adolescence. The authors suggested that reduced genetic variance in problem alcohol use in adolescence might be the consequence of large social control in adolescence. Consistent with the Button et al. study, Koopmans et al. (1999) have also found higher heritability (40\%) in alcohol use initiation among females without a religious upbringing compared with females with a religious upbringing $(0 \%)$. Based on the sample that Koopmans et al. have used, Boomsma et al. (1999) have shown that religious upbringing reduced the influence of genetic factors on disinhibition in males but not in females, suggesting that religious upbringing can moderate the genetic effects on disinhibition at least in males. However, all of these studies have focused on the moderating role of religiousness in problem behaviors and related traits, with little consideration of the moderating role in positive character traits such as PB. Frequent exposures to religious teachings that emphasize the value of $\mathrm{PB}$ may serve to activate specific genetic mechanisms underlying $\mathrm{PB}$ or restrict environmental variabilities in religious followers due to the influence that religious organizations may exert. Using the dopamine D4 receptor (DRD4) susceptibility variants, Sasaki et al. (2013) have investigated whether religion priming has $G \times E$ interaction effects to influence $\mathrm{PB}$. The authors have found that participants with DRD4 susceptibility variants were more prosocial when primed with religion than when not primed with religion, whereas participants without DRD4 susceptibility variants were not affected by religious priming. Although the Sasaki et al. study suffered from a small sample size, the results suggested that there may be a $G \times E$ interaction in the relationship between religiousness and $\mathrm{PB}$.

Using a $G \times E$ interaction modeling (Purcell, 2002), the present study aimed to examine whether and how the frequency of religious attendance (FRA) moderates genetic and environmental influences on PB in Nigerian adolescents. Nigeria is a very religious nation. Over $98 \%$ of the Nigerian population is known to be either Christian or Muslim, with the remainder having African traditional religions or no religion (Pew Research Center, 2012). It has been estimated that whereas $16.4 \%$ of the US population and $42.1 \%$ of the Dutch population are religiously unaffiliated, only about $0.4 \%$ of the Nigerian population are unaffiliated (Pew Research Center, 2012). Thus, the results of the present study may have an implication in understanding the processes of how religious attendance contributes to the development of $\mathrm{PB}$, especially in a highly religious environment.

\section{Methods \\ Sample}

The sample included 2860 adolescent twins aged 12-18 years. These were 280 (128 pairs and 24 individuals) monozygotic males (MZM), 417 (197 pairs and 23 individuals) monozygotic females (MZF), 544 (246 pairs and 52 individuals) dizygotic males (DZM), 699 (328 pairs and 43 individuals) dizygotic females (DZF), and 920 (418 pairs and 84 individuals) opposite-sex dizygotic (OSDZ) twins drawn from the Nigerian Twin and Sibling Registry (Hur et al., 2013). The mean (SD) age of these twins was 14.2 (1.7) years. In terms of religious affiliation, $64.3 \%$ of our twins identified themselves as Christian, $35.6 \%$ as Muslim and $0.1 \%$ as others. An excess of Christians found in the present sample was in line with the demographic characteristics of the population in Lagos state in Nigeria (Pew Research Center, 2012).

Twins were recruited from 272 public junior and senior secondary schools in Lagos state. The details of the recruitment procedures of the present sample can be found in Hur et al. $(2013,2017)$. Briefly, we first obtained approvals to conduct this research from the Ministry of Education in Lagos state and the Health Research and Ethics Committee of the Lagos State University Teaching Hospital in Nigeria. Then, we visited each of the 272 schools and administered the questionnaires to the twins in a library or a special classroom. During the testing session, a saliva sample was taken and analyzed to determine twins' zygosity. Eighteen microsatellite markers of DNA, including amelogenin, were analyzed to test zygosity of twins. A much larger number of dizygotic than monozygotic twins in the present sample likely reflected twin birth rates in Nigeria (MacGillivray, 1986).

\section{Measures}

Prosocial behavior (PB) scale. The PB scale of the Strengths and Difficulties Questionnaire (SDQ; Goodman, 1997) was used to assess PB. The PB scale includes five prosocial items regarding sharing, helping and being kind and considerate of others. The PB scale of the SDQ has consistently emerged from factor analysis of the SDQ items across several countries in Europe, South Asia and Africa (Stevanovic et al., 2015). Twins were instructed to rate themselves on a three-point scale $(0=$ not true to $2=$ certainly true) for each of the five items. The responses to the five items were summed to create the score of the PB scale, where higher scores represent higher levels of PB. Cronbach $\alpha$ reliability of the five items was 0.63 for the present twin sample.

Frequency of religious attendance. Self-report data on the FRA were obtained from a single question: 'How often do you attend religious service?' Twins were asked to choose one of the six response options: (1) not at all, (2) 1-2 times a year, (3) about once a month, (4) 2-3 times a month, (5) about once a week, (6) more than once a week. Frequencies of responses of the six options were $2.5 \%, 2.9 \%, 3.4 \%, 7.1 \%, 13.4 \%$ and $70.8 \%$, respectively. As the distribution of FRA was very skewed and kurtotic with a skewness of -2.2 and a kurtosis of 4.1, FRA was operationalized as a categorical variable. We combined the first four options to one category, which resulted in three categories: non-frequent attenders (2-3 times per month or less; 15.8\%), frequent attenders (about once a week; 


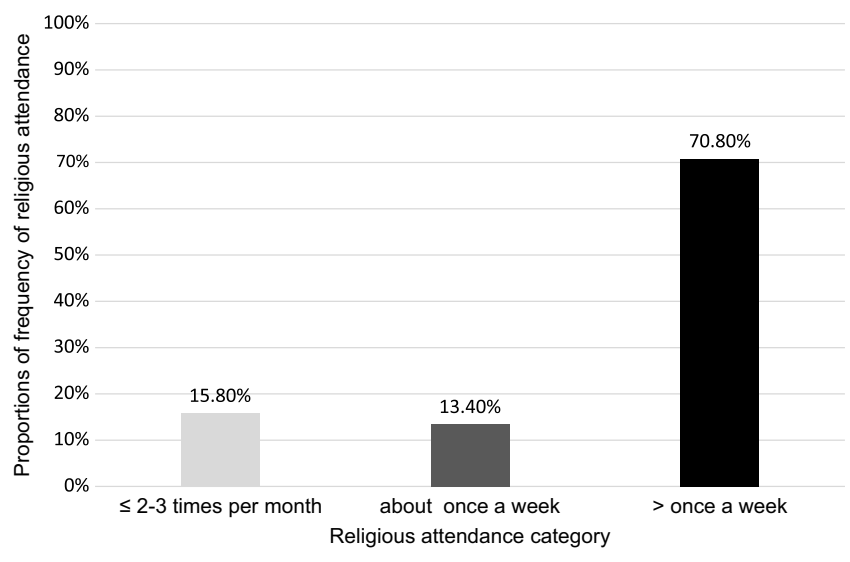

Fig. 1. Proportions of religious attendance among three categories in the study sample.

$13.4 \%$ ) and very frequent attenders (more than once a week; $70.8 \%$ ) (Figure 1).

\section{Statistical Analysis}

Polychoric correlations of FRA were estimated separately for MZM, DZM, MZF, DZF and OSDZ twins by using the raw ordinal data option in $\mathrm{Mx}$ (Neale et al., 2003). The general sex limitation model-fitting analyses were conducted to determine additive genetic (A), shared environment (C) and non-shared environment plus measurement error (E) for FRA.

As there were no significant shared genetic effects in FRA and $\mathrm{PB}$, the univariate $G \times E$ interaction model (Figure 2; Purcell, 2002) was applied to the data to determine whether genetic and environmental contributions to $\mathrm{PB}$ vary as a function of the moderator, FRA. The univariate $G \times E$ interaction model includes the standard paths, that is, additive genetic (a), shared environment (c), non-shared environmental influences and measurement error (e) and the magnitudes of moderation effects related to A, C and $\mathrm{E}$, respectively, that are allowed to vary across the levels of the moderator $(\mathrm{M})$. Thus, the phenotypic variance $(\mathrm{Vp})$ in this model can be expressed as: $\mathrm{Vp}=\left(\mathrm{a}+\beta_{\mathrm{\alpha}} \mathrm{M}\right)^{2}+\left(\mathrm{c}+\beta_{\mathrm{c}} \mathrm{M}\right)^{2}+\left(\mathrm{e}+\beta_{\mathrm{e}} \mathrm{M}\right)^{2}$. In this equation, $\beta_{\alpha}, \beta_{\mathrm{c}}$ and $\beta_{\mathrm{e}}$ represent the magnitude of the moderating effects associated with $\mathrm{A}, \mathrm{C}$ and $\mathrm{E}$, respectively. Additionally, we allowed $\mu+\beta_{\mathrm{m}} \mathrm{M}$ to represent the moderating effect of FRA on the mean of PB. To determine the best-fitting, most parsimonious model, we used the likelihood ratio test $(\mathrm{LRT})$ and Akaike's information criterion (AIC $=-2 \mathrm{LL}-2 d f$ ). Models having lower AIC are considered more parsimonious and thus preferred (Akaike, 1987).

\section{Results}

\section{Descriptive Statistics and Twin Correlations}

There were modest but significant age and sex effects on $\mathrm{PB}$ (older > younger; female $>$ male). $\mathrm{PB}$ was significantly higher in Christians than in Muslims (8.1 vs. 7.8). However, the mean difference was trivial (Cohen's $d=0.15$ ) and appeared to attain statistical significance due to a large sample. The details of the descriptive statistics for PB can be found in Hur et al. (2017). FRA was not significantly different between males and females $\left(\Delta \chi_{2}^{2}=5.0\right.$;

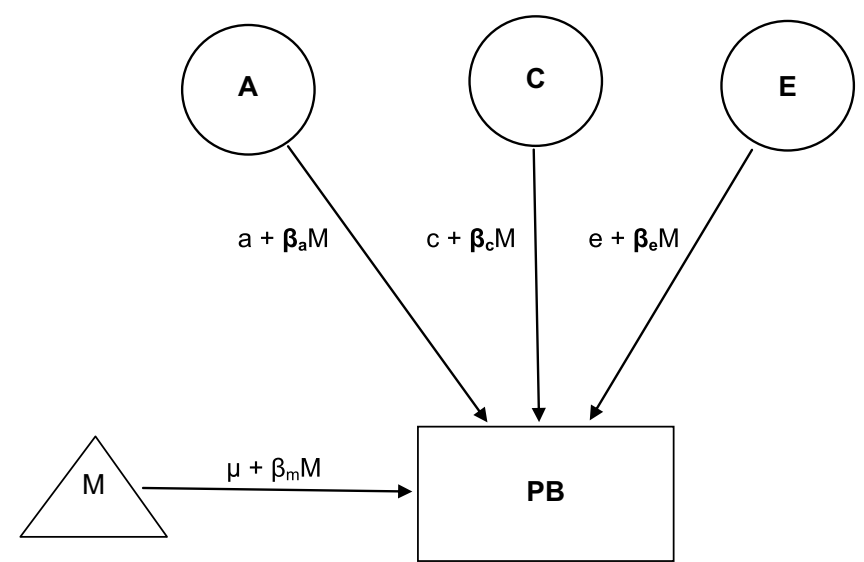

Fig. 2. Additive genetic (A), shared environment $(C)$ and non-shared environment and error (E) effects on the scores of prosocial behavior (PB). a, c and e = unmoderated genetic, shared environment and non-shared environment and error components; $\beta_{\mathrm{a}}, \beta_{\mathrm{c}}$ and $\beta_{\mathrm{e}}=$ moderated components of $\mathrm{a}, \mathrm{c}$ and e, respectively. $\beta_{\mathrm{m}}=$ main effect of moderator; $M=$ moderator; $\mu$ = grand mean. $M=$ moderator (frequency of religious attendance), $\beta=$ regression coeficient for $M$.

$p=.08)$ in our sample. We divided the total sample into junior and senior secondary school students to examine the main effect of age on FRA. However, no significant difference was found between the two age groups $\left(\Delta \chi_{2}^{2}=4.2 ; p=.12\right)$.

Maximum likelihood correlations for PB were $0.28(95 \%$ $\mathrm{CI}=0.11,0.44)$ for $\mathrm{MZM}, 0.26(95 \% \mathrm{CI}=0.13,0.38)$ for $\mathrm{DZM}$, $0.45(95 \% \mathrm{CI}=0.32,0.56)$ for $\mathrm{MZF}, 0.14(95 \% \mathrm{CI}=0.02,0.26)$ for DZF and $0.19(95 \% \mathrm{CI}=0.09,0.29)$ for OSDZ twins. The difference between monozygotic and dizygotic correlations for PB was larger in females than in males, suggesting that genetic effects on PB may be larger in females than in males. However, model-fitting analysis indicated that the magnitudes of genetic and environmental effects were not significantly different between the two sexes (Hur et al., 2017). Polychoric correlations for FRA were 0.78 $(95 \% \mathrm{CI}=0.63,0.88)$ for $\mathrm{MZM}, 0.64(95 \% \mathrm{CI}=0.51,0.74)$ for $\mathrm{DZM}, 0.75(95 \% \mathrm{CI}=0.64,0.84)$ for $\mathrm{MZF}, 0.76(95 \% \mathrm{CI}=0.67$, $0.83)$ for $\mathrm{DZF}$ and $0.76(95 \% \mathrm{CI}=0.68,0.82)$ for OSDZ twins. In both sex groups, twin correlations were very high and similar across monozygotic and dizygotic twins, suggesting the presence of substantial shared environmental influences on FRA. The OSDZ twin correlation was not lower than the correlation for DZM or DZF, providing little evidence for the presence of sexspecific genetic effects on FRA.

\section{General Sex Limitation Model-Fitting Analysis for FRA}

The general sex limitation model-fitting analysis for FRA showed that sex-specific genetic effects were not significant $\left(\Delta \chi_{1}^{2}=2.2\right.$; $p=.14)$. Furthermore, the magnitudes of additive genetic and shared and non-shared environmental influences were not significantly different between the two sexes $\left(\Delta \chi_{4}^{2}=3.9 ; p=.42\right)$. While dropping shared environmental effects from the full model significantly worsened the model fit $\left(\Delta \chi_{5}^{2}=95.6 ; p=.00\right)$, dropping additive genetic effects did not $\left(\Delta \chi_{5}^{2}=4.4 ; p=.50\right)$. From these model comparisons, we concluded that the model that included shared and non-shared environmental influences alone was the best. In the best-fitting model, shared and non-shared environmental influences were $74 \%(95 \% \mathrm{CI}=69 \%, 78 \%)$ and $26 \%(95 \%$ $\mathrm{CI}=22 \%, 31 \%)$, respectively, for both sexes. 
Table 1. Results of the univariate $G \times E$ interaction models testing for the moderating effects of the frequency of religious attendance on genetic and environmental influences on prosocial behavior

\begin{tabular}{|c|c|c|c|c|c|c|}
\hline Model & Description & $-2 \mathrm{LL}$ & $d f$ & AIC & $\Delta \chi^{2}(\Delta d f)$ & $p$ \\
\hline 2 & Drop the main effect of moderator $\left(\beta_{m}\right)$ & 6298.2 & 2305 & 1688.2 & $23.8(1)$ & .00 \\
\hline 4 & Drop moderation on $A\left(\beta_{a}\right)$ & 6277.3 & 2305 & 1667.3 & $3.0(1)$ & .08 \\
\hline 5 & Drop moderation on $C\left(\beta_{c}\right)$ & 6278.4 & 2305 & 1668.4 & $4.07(1)$ & .04 \\
\hline 7 & Drop $A$ and moderation on $A\left(\beta_{a}\right)$ & 6287.6 & 2306 & 1675.6 & $13.3(2)$ & .00 \\
\hline 8 & Drop $C$ and moderation on $C\left(\beta_{c}\right)$ & 6278.4 & 2306 & 1666.4 & $4.1(2)$ & .13 \\
\hline 9 & Drop $C$ and moderation on $C\left(\beta_{c}\right)$ and on $A\left(\beta_{a}\right)$ & 6278.9 & 2307 & 1664.9 & $4.6(3)$ & .21 \\
\hline 10 & Drop $C$ and moderation on $C\left(\beta_{c}\right)$ and on $E\left(\beta_{e}\right)$ & 6282.8 & 2307 & 1668.8 & $8.5(3)$ & .04 \\
\hline
\end{tabular}

Note: $-2 \mathrm{LL}=-2$ log-likelihood. $\mathrm{A}=$ additive genetic variance, $\mathrm{C}=$ shared environmental variance, $\mathrm{E}=$ non-shared environmental variance including measurement error. The best-fitting model is indicated in bold.

\section{$G \times E$ Model-Fitting Analysis}

The phenotypic correlation between FRA and PB was modest but positive $(r=.12 ; p<.01)$, suggesting that $\mathrm{PB}$ is higher in more frequent attenders than in less frequent attenders. This association was not significantly different between Muslims and Christians ( $r=.13$ in Christians; $r=.12$ in Muslims).

Table 1 presents the results of univariate $G \times E$ interaction analysis. When all of the moderation effects were removed from the full model simultaneously, a significant reduction in model fit occurred (model 3: $\Delta \chi_{3}^{2}=17.4 ; p=.001$ ), indicating the presence of the effects of moderation. When we removed the effect of moderation individually from the full model (models 4-6), only moderation on $A\left(\beta_{\mathrm{a}}\right)$ was not significant, suggesting that the genetic effects on $\mathrm{PB}$ were stable across all levels of FRA. While removing $\mathrm{C}$ and moderation on $\mathrm{C}$ simultaneously produced a non-significant change in chi-square (model 8: $\Delta \chi_{2}^{2}=4.1$; $p=.13$ ), removing $\mathrm{A}$ and moderation on A yielded a significant difference in chi-square (model $7: \Delta \chi_{2}^{2}=13.3 ; p=.00$ ). From model 8 , we further eliminated moderation on $A\left(\beta_{a} ;\right.$ model 9$)$ and on $\mathrm{E}\left(\beta_{\mathrm{e}} ;\right.$ model 10$)$, respectively. These procedures yielded a significant chi-square change in model 10 but not in model 9 , providing evidence for the presence of moderation on E. From these model comparisons using LRT, we concluded that model 9 was the best fitting one. AIC also suggested that model 9 was the best because it showed the lowest AIC.

Figure 3 depicts the unstandardized additive genetic, nonshared environmental and total variances, and Figure 4 depicts the standardized variances of the corresponding components. Figure 3 shows that while additive genetic variance was stable across the levels of FRA, the non-shared environmental and total variances declined with increasing levels of FRA. These results suggest that a decrease in the total variance of PB with increasing FRA was due to a reduction in non-shared environmental rather than additive genetic variance. Among non-frequent attenders, non-shared environmental variances accounted for most of the total variance of $\mathrm{PB}$, which resulted in a small heritability of PB in Figure 4. Among very frequent attenders, additive genetic variance explained a significant amount of the total variance, leading to a relatively high heritability of $\mathrm{PB}$, as indicated in Figure 4. Figure 4 shows that heritability and non-shared environmental influences on $\mathrm{PB}$ were $29 \%$ $(95 \% \mathrm{CI}=27 \%, 30 \%)$ and $71 \%(95 \% \mathrm{CI}=70 \%, 73 \%)$, respectively, among non-frequent attenders, while the corresponding estimates were $38 \%(95 \% \mathrm{CI}=33 \%, 44 \%)$ and $62 \%(95 \% \mathrm{CI}=56 \%, 67 \%)$ among very frequent attenders.

\section{Discussion}

Using a genetically informative design, the present study explored the role of religious attendance in the development of $\mathrm{PB}$ in public school twins in Nigeria. We first examined genetic and environmental influences on religious attendance in Nigerian adolescents. While genetic influence on FRA was not significant, the estimate of shared environmental influence was substantial (74\%), replicating the findings from the western adolescent twin samples (Boomsma et al., 1999; Bradshaw \& Ellison, 2008; Truett et al., 1992). However, the finding that there was no significant sex difference in FRA in the present sample was not consistent with the general finding that females are more religious than males (Trzebiatowska \& Bruce, 2012). In the questionnaire given to twins, we included an item asking their parents' religious affiliation. Over $98 \%$ of our twins reported that they had the same religious affiliation that their parents had. Thus, the sources of shared environment in religious attendance in the present sample were likely to be parental factors such as parents' religious attendance, expectations, values and assortative mating for religious attendance (Truett et al., 1994).

The phenotypic correlation between religious attendance and $\mathrm{PB}$ in the present sample was significant but modest $(r=.12)$, which was in line with the findings from Stavrova and Siegers (2014). This correlation was also close to the finding from the Donahue and Benson study (1995) where the authors have reported a correlation of $.11(p<.01)$ between altruism and church attendance in a large national sample of US adolescents. The result of $\mathrm{G} \times \mathrm{E}$ model-fitting analysis using FRA as an environmental moderator showed environment-environment $(E \times E)$ rather than $\mathrm{G} \times \mathrm{E}$ interaction: environmental experiences explained more of the variance in $\mathrm{PB}$ in less frequent religious attenders. Adolescents at the low end of the FRA were likely from non-religious households and learned PB from various sources rather than religious organizations. A large non-shared environmental variance found in adolescents at the low end of the FRA suggests that there were great variabilities in the prosocial characteristics of the peers and experiences of socialization, perhaps because these adolescents were relatively free from religious constraints. Due to the large 


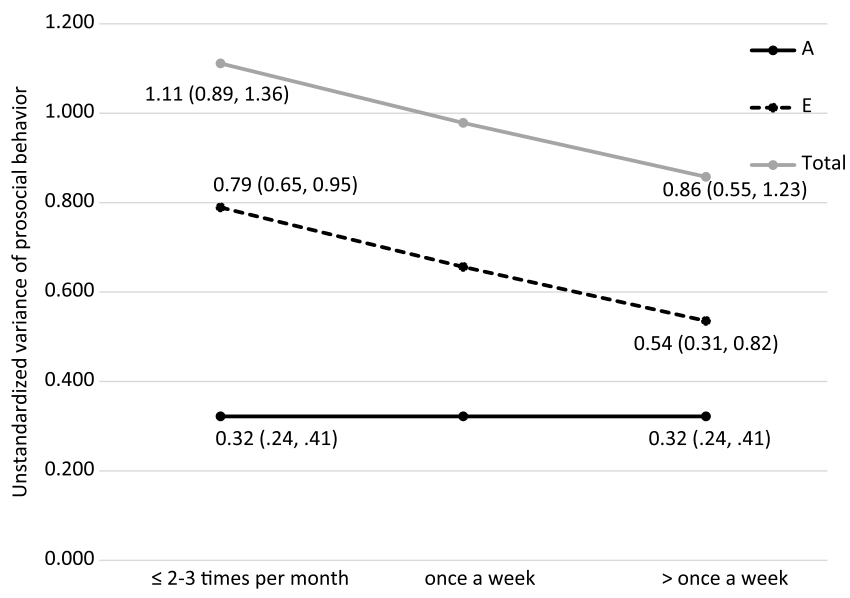

Fig. 3. Unstandardized additive genetic (A) and non-shared environment including measurement error (E) variances, and the total variance of prosocial behavior (PB) as a function of the frequency of religious attendance (FRA) in the best-fitting model ( $95 \% \mathrm{Cls}$ are in parentheses).

non-shared environmental influences, the relative influence of genetic factors on $\mathrm{PB}$ was small among adolescents at the low end of the FRA. In contrast, adolescents at the high end of the FRA were from very religious families and were likely associated with religious peers who share and promote prosocial values. These adolescents were very frequently exposed to religious teachings that encourage practices of $\mathrm{PB}$. We speculate that these religious atmospheres substantially attenuated the variation of the non-shared environment among adolescents at the high end of the FRA. Due to the reduction in non-shared environment, the relative influence of genetic factors in this group was high. The implication of our finding is that frequent religious attendance can change individual environmental experiences rather than genetic effects on PB, which may result in an increase in the mean level and a decrease in the total variability of $\mathrm{PB}$.

The lack of a significant moderating effect on genetic variation in PB in our study is in contrast to the results of the Sasaki et al.'s study (2013) and previous quantitative $\mathrm{G} \times \mathrm{E}$ studies that have examined the moderating role of religiousness (Boomsma et al., 1999; Button et al., 2010; Koopmans et al., 1999). However, the Sasaki et al. study was based on the candidate-gene approach, which has been criticized for a high rate of false-positives (Sullivan, 2007). Prior quantitative $G \times E$ studies have focused on problem behaviors such as substance abuse or the initiation of substance use in adolescents, while our study examined a positive trait. Thus, whether or not religiousness can moderate genetic variations in positive traits such as PB awaits replications in other samples.

The present study has several limitations. First, we used FRA as a proxy measure of religiousness. However, it has been suggested that the measure of FRA underestimates the complexity of the religiousness construct (Hills \& Pargament, 2003). It is, therefore, important in future studies to investigate whether and how other aspects of religiousness interact with genetic and environmental influences on PB. Prior studies have shown that personal forms of religiousness such as praying to God showed higher genetic influences than do social forms of religiousness such as church attendance (Hvidtjørn et al., 2013). Thus, the pattern of $G \times E$ may be different from our findings if we employ measures of a personal form of religiousness. Second, as our measures of FRA and PB are both self-reported, twins' responses may have been contaminated by social desirability because more religious individuals tend

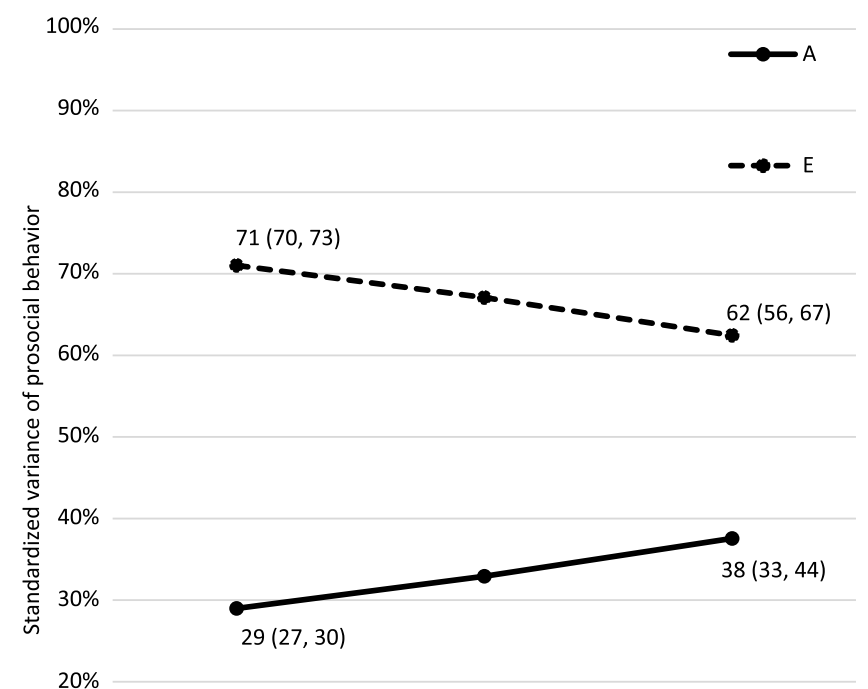

$10 \%$

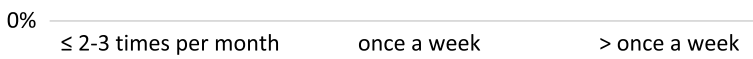

Fig. 4. Standardized additive genetic (A) and non-shared environment including measurement error variances (E) of prosocial behavior (PB) as a function of the frequency of religious attendance (FRA) in the best-fitting model ( $95 \%$ Cls are in parentheses).

to inflate self-ratings of prosocial characteristics (Galen, 2012). However, several researchers have indicated that the relationship between religiousness and $\mathrm{PB}$ remained significant even when social desirability was controlled (e.g., Lewis, 1999, 2000; Saroglou et al., 2005). Third, the present sample consisted of adolescents aged 12-18 years. As prior studies have shown that genetic and environmental influences on religious attendance change with age, the patterns of $G \times E$ interaction found in the present study may differ in adulthood. For instance, given an increase in genetic influences on religious attendance with age, gene-environment correlation between religious attendance and PB may be found to be significant in adulthood. Finally, our sample only comprised adolescent twins attending public schools in Lagos state, Nigeria. Thus, it remains to be seen whether or not the present findings extend to other ethnic groups or regions in Nigeria.

Acknowledgments. This research was supported by the Charles Darwin Research Institute (USA) and the Ulster Institute for Social Research (UK) to the first author (Y.M.H.). I would like to thank the twins who participated in this study, and school teachers and principals in the public schools in Lagos state, the staff members in the Ministry of Education in Lagos state and many research assistants who kindly assisted this study. Special thanks are given to Human Pass, Korea, who assisted us with twins' zygosity testing.

\section{References}

Akaike, H. (1987). Factor analysis and AIC. Psychometrika, 52, 317-332.

Benson, P. L., Scales, P. C., Sesma, A., \& Roehlkepartain, E. C. (2006). Adolescent spirituality. Adolescent and Family Health, 4, 41-51.

Boomsma, D. I., de Geus, E. J., van Baal, G. C., \& Koopmans, J. R. (1999). A religious upbringing reduces the influence of genetic factors on disinhibition: Evidence for interaction between genotype and environment. Twin Research, 2, 115-125.

Bradshaw, M., \& Ellison, C. G. (2008). Do genetic factors influence religious life? Findings from a behavior genetic analysis of twin siblings. Journal for the Scientific Study of Religion, 47, 529-544. 
Button, T. M., Hewitt, J. K., Rhee, S. H., Corley, R. P., \& Stallings, M. C. (2010). The moderating effect of religiosity on the genetic variance of problem alcohol use. Alcoholism, Clinical and Experimental Research, 34, 1619-1624.

Campbell, M. C., \& Tishkoff, S. A. (2008). African genetic diversity: Implications for human demographic history, modern human origins, and complex disease mapping. Annual Review of Genomics and Human Genetics, 9, 403-433.

Decety, J., Cowell, J. M., Lee, K., Mahasneh, R., Malcolm-Smith, S., Selcuk, B., \& Zhou, X. (2015). The negative association between religiousness and children's altruism across the world. Current Biology, 25, 2951-2955.

Donahue, M. J., \& Benson, P. I. (1995). Religion and the well-being of adolescents. Journal of Social Issues, 51, 145-160.

Eaves, L. J., Hatemi, P. K., Prom-Womley, E. C., \& Murrelle, L. (2008). Social and genetic influences on adolescent religious attitudes and practices. Social Forces, 86, 1621-1646.

Furrow, J. L., King, P. E., \& White, K. (2004). Religion and positive youth development: Identity, meaning, and prosocial concerns. Applied Developmental Science, 8, 17-26.

Galen, L. W. (2012). Does religious belief promote prosociality? A critical examination. Psychological Bulletin, 138, 876-906.

Goodman, R. (1997). The strengths and difficulties questionnaire: A research note. Journal of Child Psychology and Psychiatry, 38, 581-586.

Gregory, A. M., Light-Häusermann, J. H., Rijsdijk, F., \& Eley, T. C. (2009). Behavioral genetic analyses of prosocial behavior in adolescents. Developmental Science, 12, 165-174.

Hills, P. C., \& Pargament, K. I. (2003). Advances in the conceptualization and measurement of religion and spirituality. American Psychologist, 58, 64-74.

Hur, Y.-M., Kim, J. W., Chung, K. W., Shin, J. S., Jeong, H.-U., \& Auta, E. (2013). The Nigerian twin and sibling registry. Twin Research and Human Genetics, 16, 282-284.

Hur, Y.-M., \& Rushton, J. P. (2007). Genetic and environmental contributions to prosocial behaviour in 2- to 9-year-old South Korean twins. Biological Letters, 22, 664-666.

Hur, Y. M., Taylor, J., Jeong, H. U., Park, M. S., \& Haberstick, B. C. (2017). Perceived family cohesion moderates environmental influences on prosocial behavior in Nigerian adolescent twins. Twin Research and Human Genetics, $20,1-10$.

Hvidtjørn, D., Petersen, P., Hjelmborg, J., Skytthe, A., Christensen, K., \& Hvidt, N. C. (2013). Familial resemblance in religiousness in a secular society: A twin study. Twin Research and Human Genetics, 16, 544-553.

Kendler, K. S., \& Myers, J. (2009). A developmental twin study of church attendance and alcohol and nicotine consumption: A model for analyzing the changing impact of genes and environment. American Journal of Psychiatry, 166, 1150-1155.

Kirk, K. M., Maes, H. H., Neale, M. C., Heath, A. C., Martin, N. G., \& Eaves, L. J. (1999). Frequency of church attendance in Australia and the United States: Models of family resemblance. Twin Research, 2, 99-107.

Knafo, A., \& Plomin, R. (2006). Parental discipline and affection and children's prosocial behavior: Genetic and environmental links. Journal of Personality and Social Psychology, 90, 147-164.

Koenig, L. B., McGue, M., Krueger, R. F., \& Bouchard, T. J., Jr. (2005). Genetic and environmental influences on religiousness: Findings for retrospective and current religiousness ratings. Journal of Personality, 73, 471-488.

Koenig, L. B., McGue, M., Krueger, R. F., \& Bouchard, T. J., Jr. (2007). Religiousness, antisocial behavior, and altruism: Genetic and environmental mediation. Journal of Personality, 75, 265-290.
Koopmans, J. R., Slutske, W. S., van Baal, G. C., \& Boomsma, D. I. (1999). The influence of religion on alcohol use initiation: Evidence for genotype $\times$ environment interaction. Behavior Genetics, 29, 445-453.

Lewis, C. A. (1999). Is the relationship between religiosity and personality 'contaminated' by social desirability as assessed by the Lie Scale? A methodological reply to Michael W. Eysenck (1998). Mental Health, Religion and Culture, 2, 105-114.

Lewis, C. A. (2000). The religiosity-psychoticism relationship and the two factors of social desirability: A response to Michael W. Eysenck (1999). Mental Health, Religion and Culture, 3, 39-45.

MacGillivray, I. (1986). Epidemiology of twin pregnancy. Seminars in Perinatology, 10, 4-8.

Neale, M. C., Boker, S. M., Xie, G., \& Maes, H. H. (2003). Mx: Statistical modeling. Richmond, VA: Department of Psychiatry, Virginia Commonwealth University Medical School.

Norenzayan, A., \& Shariff, A. F. (2008). The origin and evolution of religious prosociality. Science, 322, 58-62.

Pew Research Center. (2012). The global religious landscape: Religious composition by country, in numbers and percentage. Retrieved from http:// www.pewforum.org/2012/12/18/table-religious-composition-by-country-inpercentages

Purcell, S. (2002). Variance components models for gene-environment interaction in twin analysis. Twin Research, 5, 554-571.

Saroglou, V., Pichon, I., Trompette, L., Verschueren, M., \& Dernelle, R. (2005). Prosocial behavior and religion: New evidence based on projective measures and peer ratings. Journal for the Scientific Study of Religion, 44, 323-348.

Sasaki, J. Y., Kim, S. H., Mojaverian, T., Kelley, L. D. S., Park, I. Y., \& Janusonis, S. (2013). Religion priming differentially increases prosocial behavior among variants of the dopamine D4 receptor (DRD4) gene. Scan, 8, 209-215.

Scourfield, J., John, B., Martin, N., \& McGuffin, P. (2004). The development of prosocial behavior in children and adolescents: A twin study. Journal of Child Psychology and Psychiatry, 45, 927-935.

Shariff, A. F., Willard, A. K., Andersen, T., \& Norenzayan, A. (2016). Religious priming: A meta-analysis with a focus on prosociality. Personality and Social Psychology Review, 20, 27-48.

Stavrova, O., \& Siegers, P. (2014). Religious prosociality and morality across cultures: How social enforcement of religion shapes the effects of personal religiosity on prosocial and moral attitudes and behaviors. Personality \& Social Psychology Bulletin, 40, 315-333.

Stevanovic, D., Urbán, R., Atilola, O., Vostanis, P., Singh Balhara, Y. P., Avicenna, M., ... Petrov, P. (2015). Does the strengths and difficulties questionnaire - Self report yield invariant measurements across different nations? Data from the International Child Mental Health Study Group. Epidemiology and Psychiatric Sciences, 24, 323-334.

Sullivan, P. F. (2007). Spurious genetic associations. Biological Psychiatry, $61,1121-1126$.

Truett, K. R., Eaves, L. J., Meyer, J. M., Heath, A. C., \& Martin, N. G. (1992). Religion and education as mediators of attitudes: A multivariate analysis. Behavior Genetics, 22, 43-62.

Truett, K. R., Eaves, L. J., Walters, E. E., Heath, A. C., Hewitt, J. K., Meyer, J. M., ... Kendler, K. S. (1994). A model system for the analysis of family resemblance in extended kinships of twins. Behavior Genetics, 24, 35-49.

Trzebiatowska, M., \& Bruce, S. (2012). Why are women more religious than men? Oxford, UK: Oxford University Press.

Winter, T., Kaprio, J., Viken, R. J., Karvonen, S., \& Rose, R. (1999). Individual differences in adolescent religiosity in Finland: Familial effects are modified by sex and region of residence. Twin Research, 2, 108-114. 